\title{
Laboratory evaluation of selective in situ refractive cornea collagen shrinkage with continuous wave infrared laser combined with transepithelial collagen cross-linking: a novel refractive procedure
}

\author{
This article was published in the following Dove Press journal: \\ Clinical Ophthalmology \\ 27 April 2012 \\ Number of times this article has been viewed
}

\section{Anastasios John \\ Kanellopoulos}

LaserVision gr Institute, Athens, Greece; New York University Medical School, New York City, NY, USA
Correspondence:Anastasios John Kanellopoulos

New York University Medical School, New York City, NY, USA

Email ajk@brilliantvision.com
Background: This research comprised a laboratory evaluation of a novel refractive surgery technique involving sequential corneal subsurface shrinkage-driven reshaping using a continuous wave mid-infrared laser application followed by stiffening via rapid transepithelial higher fluence collagen cross-linking for shape persistence/longevity on cadaver corneas.

Materials and methods: Ten cadaver corneas were used in this study. During use, all were affixed in an artificial chamber. Thermal delivery entailed a continuous wave laser at $2013 \mathrm{~nm}$ wavelength, approximately $650 \mathrm{~mW}$ power under scanner control (about $3 \mathrm{~mm} / \mathrm{sec}$ linear draw speed), with a planoconcave sapphire applanation lens cooled to $8^{\circ} \mathrm{C}$. Group $1(\mathrm{n}=5$, myopic treatment) eyes were exposed to three concentric annuli with diameters of $3 \mathrm{~mm}, 4 \mathrm{~mm}$, and $5 \mathrm{~mm}$. Group 2 ( $\mathrm{n}=5$, hyperopic treatment) eyes were exposed to three concentric annuli with diameters of $6 \mathrm{~mm}, 7 \mathrm{~mm}$, and $8 \mathrm{~mm}$. The clinical change in shape of the cornea was visualized immediately under a slit-lamp. A transepithelial higher fluence corneal collagen cross-linking step followed each thermal treatment, comprising $0.1 \%$ riboflavin drops with $0.02 \%$ benzalkonium chloride and $0.2 \%$ carboxymethlycellulose in deuterated water $\left(\mathrm{D}_{2} \mathrm{O}\right)$ applied on the epithelium corneal surface for 10 minutes. Next, each cornea was exposed to $10 \mathrm{~mW} / \mathrm{cm}^{2}$ of ultraviolet A $(365 \mathrm{~nm})$ light for 10 minutes. The corneas were evaluated before and after thermal remodeling and cornea collagen cross-linking for corneal topography, corneal optical coherence tomography, cornea Scheimpflug tomography, and clinical photographs.

Results: The histopathology effect was noted clinically as concentric white rings underneath the epithelium and Bowman's membrane, with the lesion depth extending down to $400 \mu \mathrm{m}$ in the mid stroma of the cornea. This was confirmed by corneal anterior segment optical coherence tomography. The topographic change noted was a 4-8 diopter hyperopic shift in group 1 and a 2-6 diopter myopic shift in group 2 .

Conclusion: This novel refractive surgery technique appears to generate a significant refractive change (+/-) in the cornea, without affecting the epithelium or Bowman's membrane and without any visible epithelial defect. The transepithelial collagen cross-linking used as a second step in the same procedure aims to stabilize this effect in the long term. Further clinical studies are planned to validate these initial clinical results.

Keywords: cornea collagen shrinkage, refractive cornea change, cornea collagen cross-linking, infrared laser

\section{Introduction}

Historical attempts at reshaping corneal collagen, such as conductive keratoplasty and laser thermal keratoplasty, in order to achieve a refractive change, have been studied 
extensively in ophthalmology. ${ }^{1-14}$ A particular attraction of these procedures has been the nonablative tissue-sparing reshaping result, while a common concern has been stability/ regression of effect, hence long-term predictability. Recently, the Keraflex ${ }^{\circledR}$ two-step procedure (Avedro, Waltham, MA) has been reported to utilize a contact probe which deposits microwave thermal energy onto the anterior cornea, inducing collagen shrinkage. ${ }^{14-18} \mathrm{~A}$ circular epithelial defect has been noted immediately postoperatively. This thermal step is sequenced by lesional collagen cross-linking in order to establish longevity of the corneal remodeling achieved by the thermal effect of this procedure.

We report herein a novel in situ thermal reshaping application in which a continuous wave infrared laser is used to create selective collagen shrinkage in the anterior to mid stroma, without affecting the corneal epithelium or Bowman's membrane or endothelium, then applying high irradiance ultraviolet light with a customized riboflavin formulation for collagen cross-linking to stiffen collagen for persistence of this refractive effect in a laboratory model.

\section{Materials and methods}

Ten cadaver eyes, provided by the Eye-Bank for Sight Restoration (New York, NY) were utilized on a single-use artificial chamber (Katena, Denville, NJ). The corneas were carefully handled so as to not disturb their epithelium, with instillations of Vidilac preserved artificial tears (Bausch and Lomb Dublin, Ireland, see Figures 1 and 2). The corneas

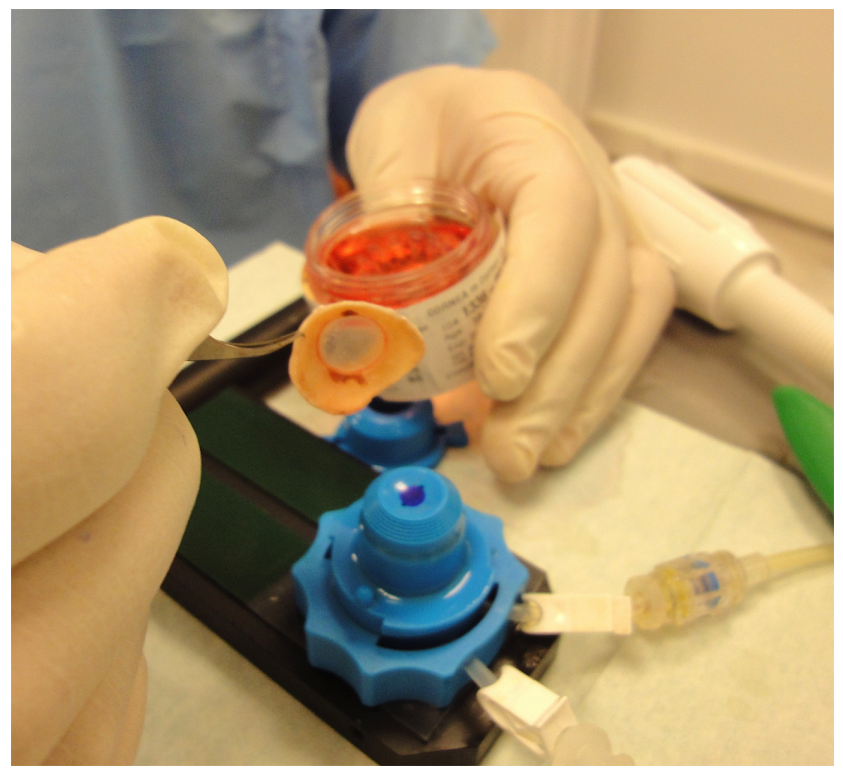

Figure I Preparation of the donor cornea from the storage vial (Optisol ${ }^{\circledR}$ solution; Oxonica, Haddenham, UK) onto the Katena ${ }^{\circledR}$ artificial anterior chamber (Katena Products, Inc, Denville, NJ).

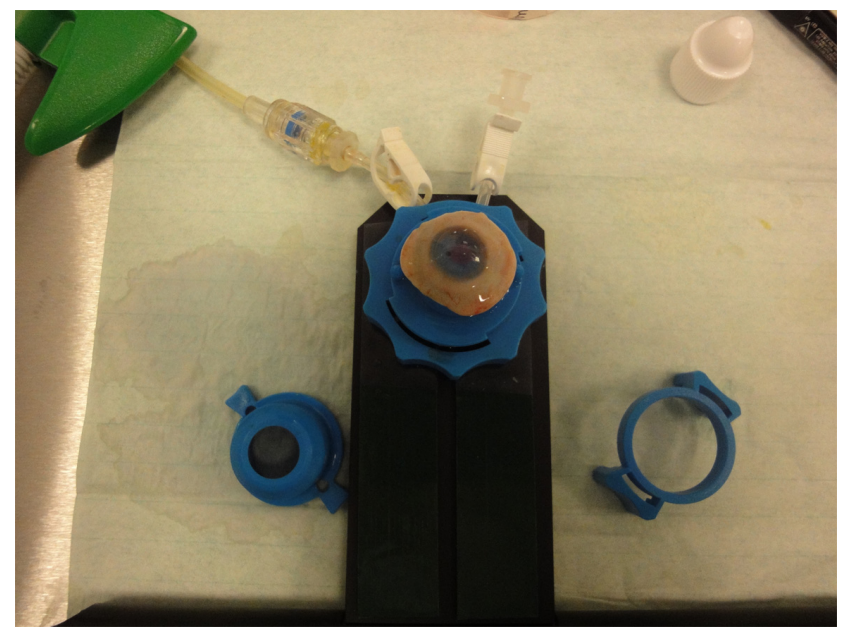

Figure 2 Donor cornea is fixated in the artificial anterior chamber and pressurized to $30 \mathrm{mmHg}$ to mimic in vivo physiology and reduce edema.

were imaged before and after treatment with corneal optical coherence tomography (Optovue, Freemont, CA, Figure 3), Placido disc corneal topography (Topolyzer; Wavelight, Erlagen, Germany) and a Scheimpflug cornea tomography device (Oculyzer; Wavelight; Figure 4) were used in order to establish baseline corneal parameters, ie, texture and anatomy, as well as cornea curvature and refractive power. Next, the corneas were placed under the prototype continuous wave infrared laser device articulating arm.

The novel infrared laser device consisted of a mid infrared $2013 \mathrm{~nm}$ laser-generating element coupled to a PC-controlled scanner (Figure 5) via a fiber and focused onto the cornea through an applanated chilled sapphire lens housed in a

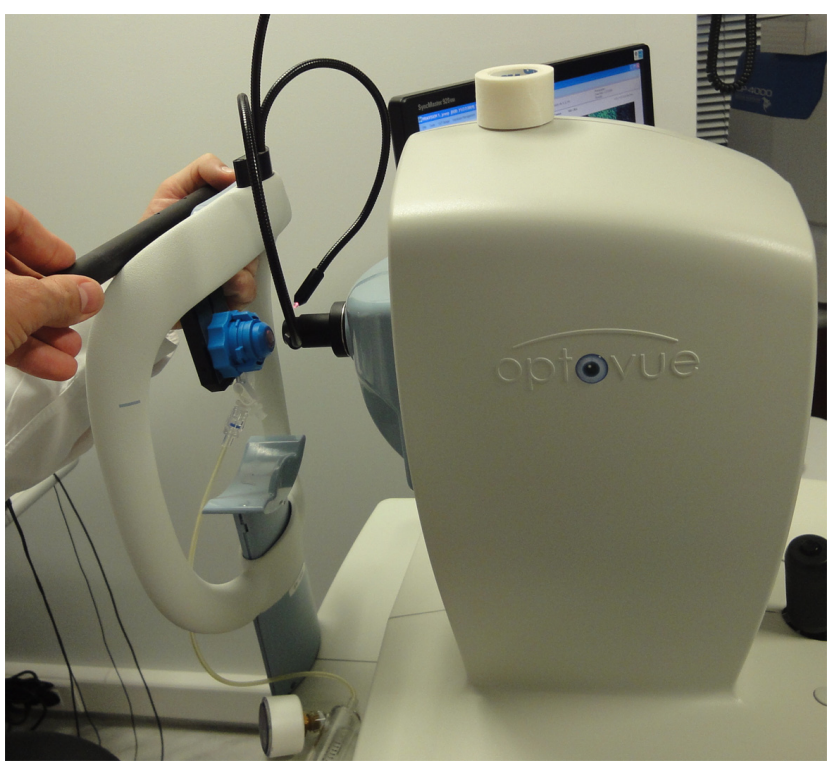

Figure 3 Fixated donor cornea scanned with Optovue cornea optical coherence tomography (Optuvue, Inc, Freemont, CA). 


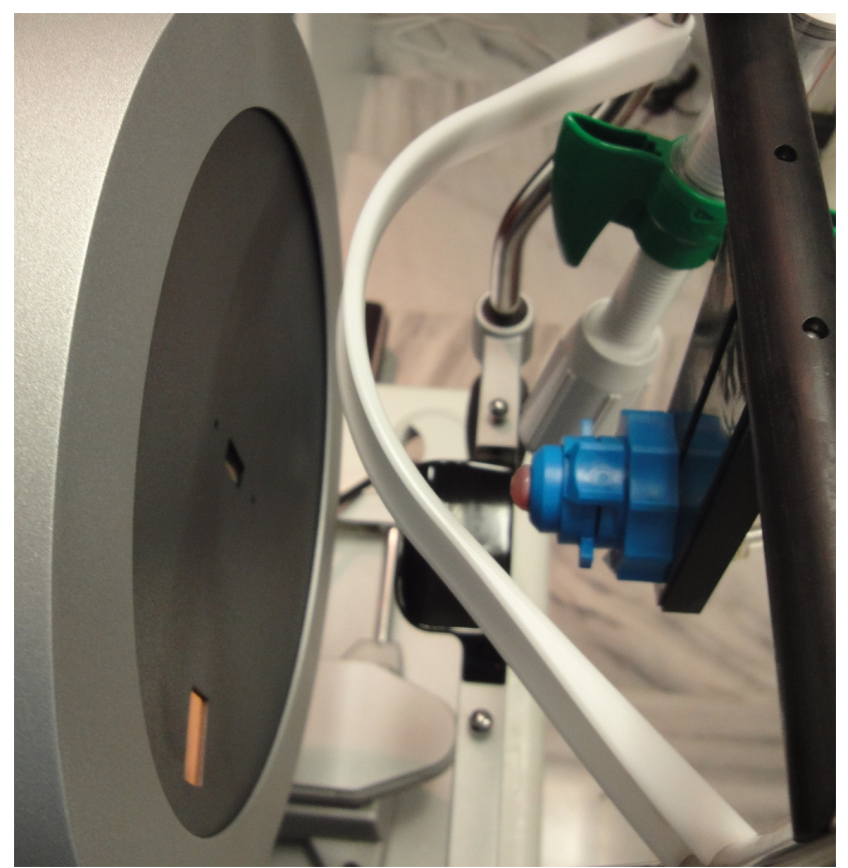

Figure 4 Fixated donor cornea scanned with Oculyzer (Pentacam) Scheimpflug cornea tomography (Wavelight).

cone assembly on the articulating arm (Figures 6 and 7). The sapphire lens was cooled to about $8^{\circ} \mathrm{C}$. The laser device was lowered to applanate the cornea (Figure 8), and this was directly visualized by the operator through the superior opening of the cone (Figure 9), and also on the PC output from the camera. Each cadaver cornea was marked in the center with a permanent marker, and this mark was used during the experimental treatment as the pupil center analog for centration.

Ring diameters and the sequence of patterns with speed and power were settable on the PC screen by the surgeon. Due to such extensive flexibility in laser depth, diameter, draw

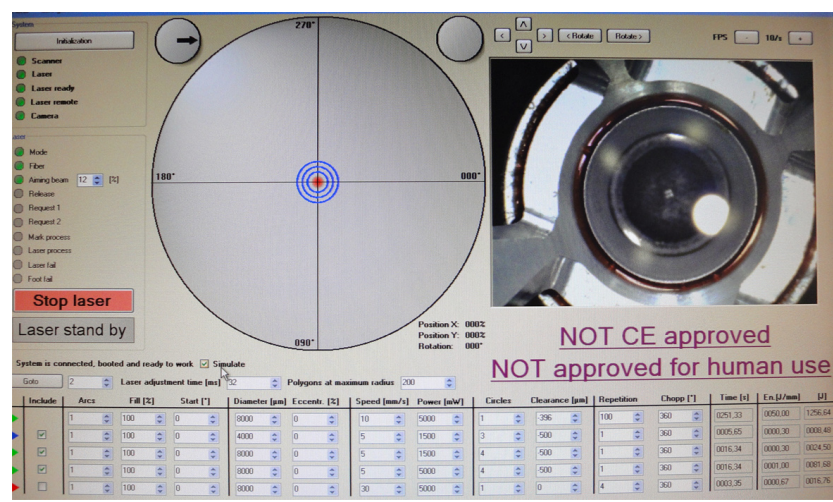

Figure 5 Computer screen of the novel treatment device. On the left of the screen, the user can visualize the planned concentric ring treatment. All parameters of these rings are customizable (diameter, spacing, number, centration, and arc). On the right of the screen, the applanated cornea and its centration is visualized.

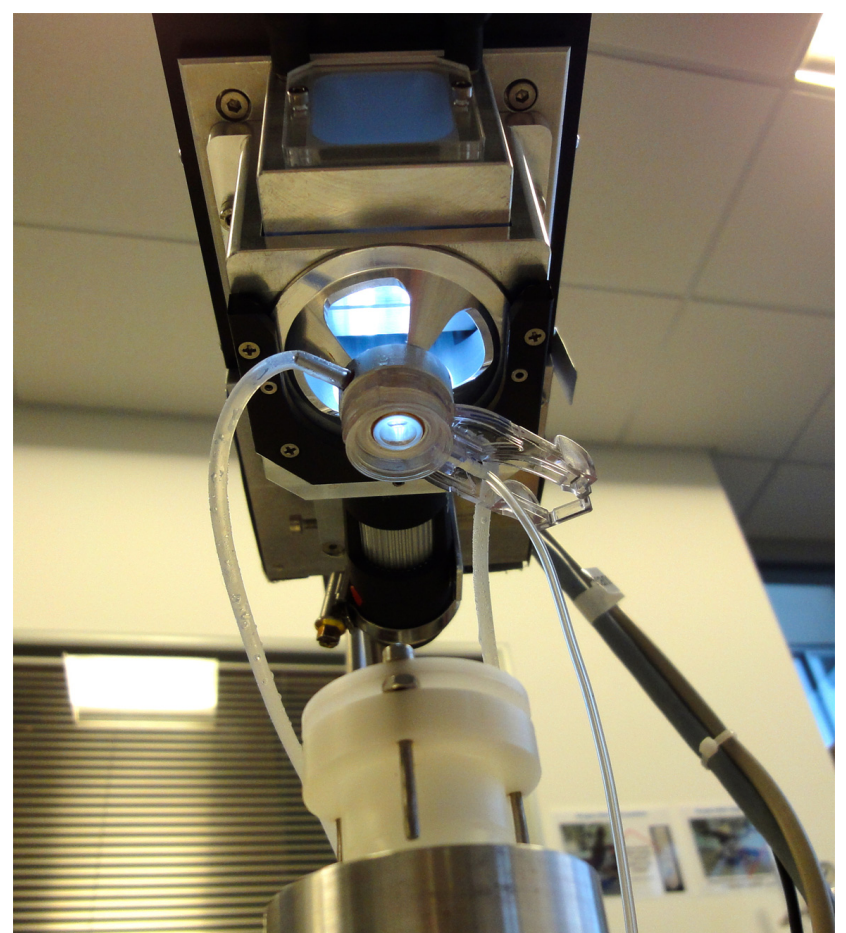

Figure 6 Cornea interface cone that comes into contact with the cornea to be treated with a cooled sapphire crystal interface.

speed, and power control, significant precision of outcomes (diopters of correction) was provided by the device.

Following an applanated cooling period of 30 seconds, the treatment was started under the control of a foot switch. It should be noted that key parameters of the laser application were specified by the surgeon at the start of each exposure. The surgeon could select one, two, three, or up to seven ring

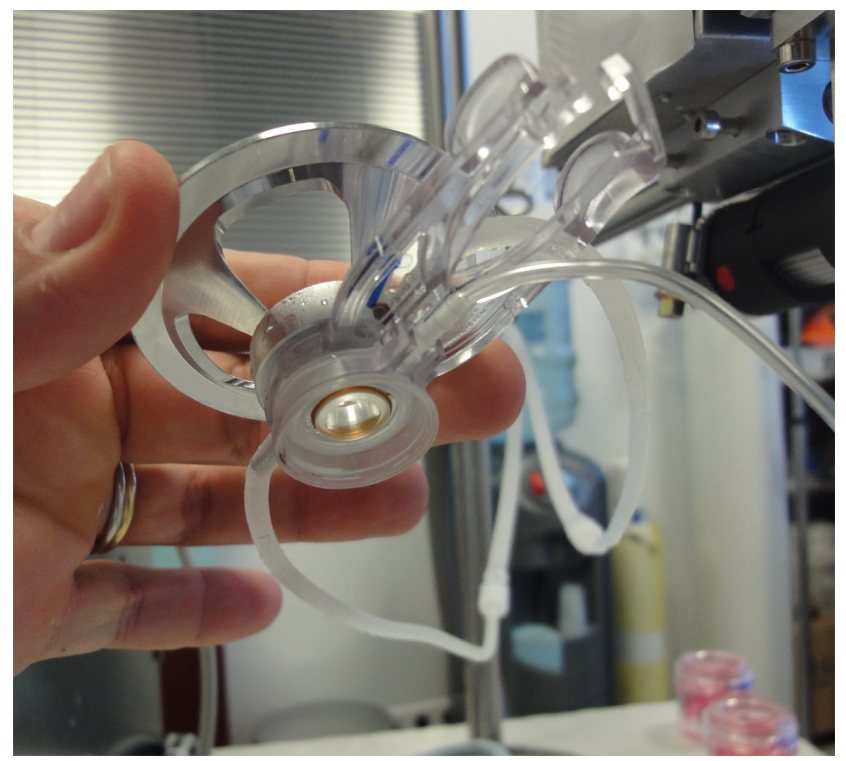

Figure 7 Different angle of the same interface seen in Figure 6. 


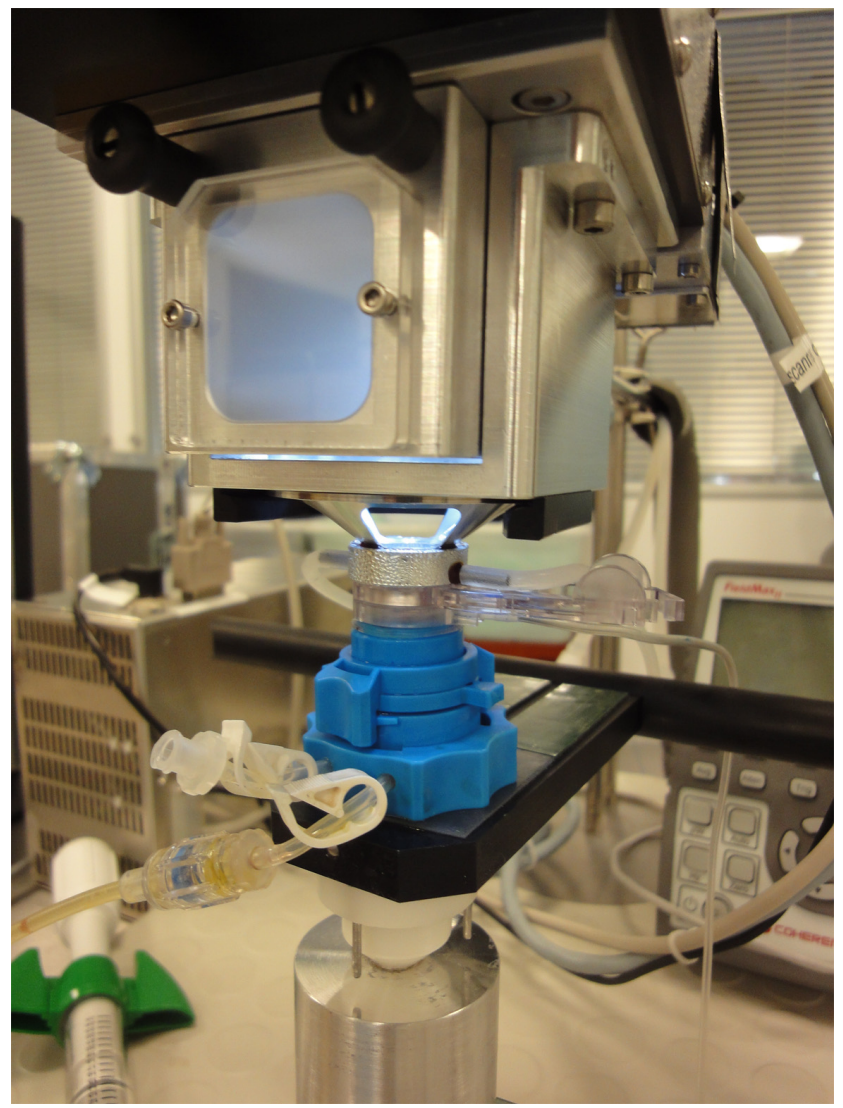

Figure 8 Interface is engaged onto the cornea to be treated. The stainless steel ring above the sapphire crystal appears to be condensing moisture, an indication of the cooling effect of the sapphire crystal.

applications in sequence. These rings can be placed anywhere on the applanated surface of the cornea (including selectively and precisely decentered), and visualized on the computer screen. Intraring distance was set as per the surgeon's preference. Based on preliminary unpublished work that

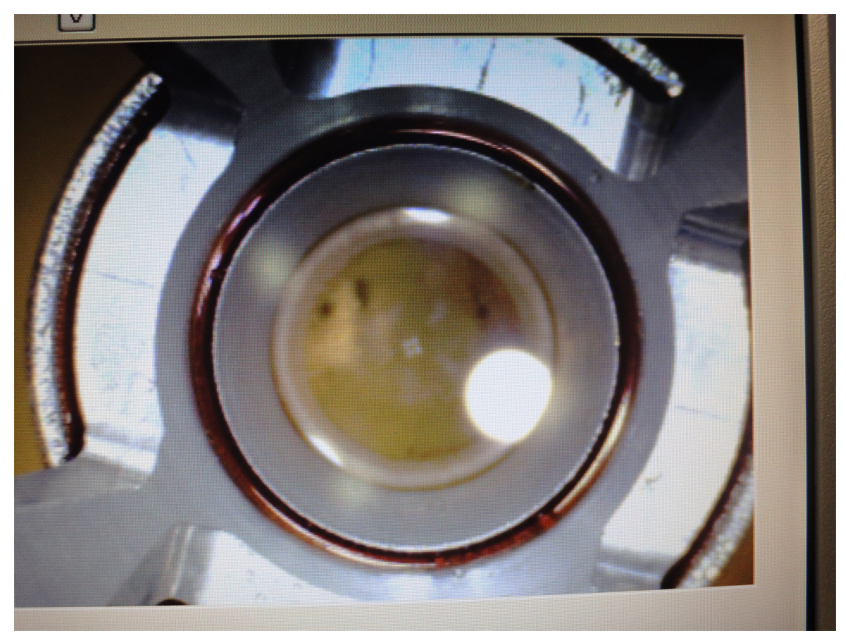

Figure 9 Operator's view of the applanated cornea through the laser device, establishing proper centration. we have done with this device for correction of myopia, we decided to place the three lesional rings at diameters of $3 \mathrm{~mm}, 4 \mathrm{~mm}$ and $5 \mathrm{~mm}$, each planned to focus laser treatment at a depth of $100 \mu \mathrm{m}$ and centered on the cornea.

The device was activated by a foot switch, and each ring was created through a continuous wave laser, applying the laser energy in a circular counterclockwise fashion, to create a complete circular subsurface ring lesion. First, the $3 \mathrm{~mm}$ diameter ring was completed, then the $4 \mathrm{~mm}$ diameter ring, and finally the $5 \mathrm{~mm}$ diameter ring. The total laser application per ring lasts about 4 seconds, and complete applanation of the arm on the cornea lasted under one minute ( 30 seconds +12 seconds +15 seconds). The system is designed to provide constant but selectable linear draw speeds at each diameter, thus inducing a uniform quality of lesion.

Following infrared laser delivery, cooling was continued for a further 15 seconds. Next, the applanation device was disengaged from the cornea. The cornea was then evaluated under the slit-lamp, and slit-lamp photographs were taken. The clinical effect of laser treatment was clearly evident as white opaque circular rings within the corneal stroma. There was no epithelial defect noted on the cornea surface, and corneal shrinkage noted on the slit-lamp was evaluated to be at about half the cornea depth. This was then further evaluated by corneal optical coherence tomography and corneal Placido disc-based topography and Scheimpflug tomographic mapping.

The hyperopic treatment was very similar to the myopic treatment described earlier, with the difference being that the concentric rings were applied at $6 \mathrm{~mm}, 7 \mathrm{~mm}$, and $8 \mathrm{~mm}$ diameters from the center of the applanated cornea. On completion of laser application, the corneas were placed in a proprietary $0.1 \%$ riboflavin solution for half an hour, and then exposed to $10 \mathrm{~mW} / \mathrm{cm}^{2}$ ultraviolet light for 10 minutes to obtain corneal collagen cross-linking.

\section{Results}

Five corneas subjected to myopic treatment showed a very similar slit-lamp and corneal optical coherence tomography effect. Corneal shrinkage was achieved, starting at about $100 \mu \mathrm{m}$ in depth and extending down to about $300 \mu \mathrm{m}$ in depth, with an annulus thickness of about $800 \mu \mathrm{m}$. There was no change in the corneal epithelium, while corneal topography showed flattening of the cornea (Figure 10, treated cornea does not stain with fluorescein), creating a hyperopic shift, which ranged from 4 to 8 diopters with a mean change of 6.5 diopters (Figure 11, corneal optical coherence tomography 


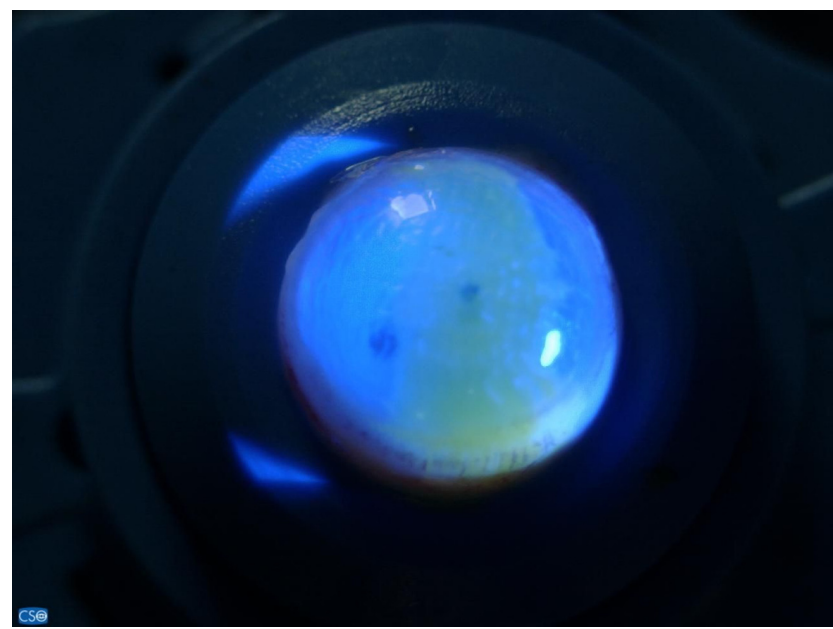

Figure $10 \mathrm{~A}$ laser-treated cornea, stained with fluorescein dye, shows no signs of epithelial injury.

showing corneal shrinkage as a dense hyper-reflective spot). Figures 12 and 13 show representative myopic treatment (pre, post, and difference).

Similar results were found in the hyperopic group, in which the myopic shift (steepening) of the central cornea was found to be 2-6 diopters, with an average diopter change of 4.2 in the central cornea. Figure 14 shows a representative hyperopic treatment (pre-, post-, and difference). Clinical pictures of the corneas following treatment are shown in Figure 15.

\section{Discussion}

We hypothesize that quality of vision outcome is related to quality of the lesion, including its position and size characteristics within the three-dimensional stromal collagen matrix. We have seen that shrinkage from thermal lesions at a programmable diameter/depth can be titrated to control

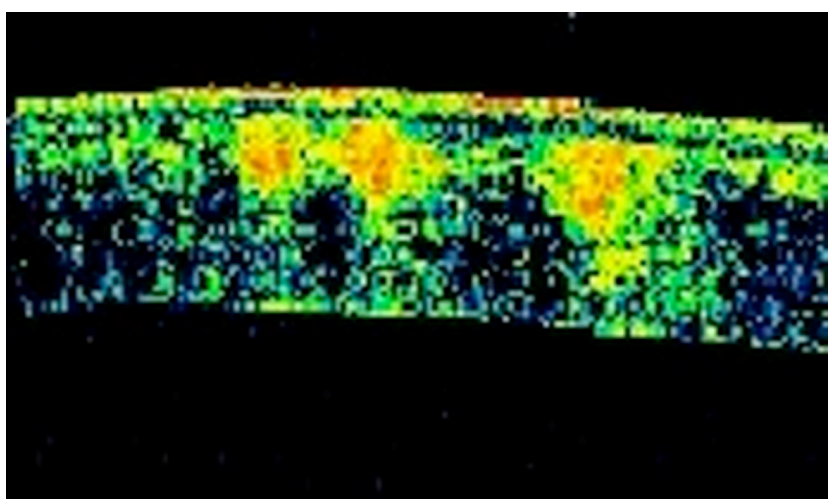

Figure I I Optical coherence tomography image of a laser-treated cornea, showing three dense mid-anterior stromal lesions, and no epithelial disturbance. the changes in the shape of the corneal surface that persist following cross-linking. This epithelium-sparing, reshaping, and stabilizing technique is clearly a novel approach in refractive manipulation of the cornea. Our small laboratory study shows a remarkable refractive change immediately after delivery that was relatively consistent in all the corneas.

An interesting finding was the fact that laser application did not affect the corneal epithelium or in most cases the Bowman's membrane at all. The actual location of the ring lesion was very close to the planned dimensions. There was no abrasion or thermal effect on the corneal epithelium and thus the nerve plexus was likely to have been preserved. Laser application appeared to cause collagen shrinkage that could be constrained ("endothelium-sparing") as needed to a corneal depth of approximately $50 \%$. This was confirmed on evaluation of the cornea after the procedure, as well as by corneal optical coherence tomography.

We also used transepithelial higher fluence corneal collagen cross-linking in order to help maintain an intact epithelium, which is the unique aspect of this procedure. Although transepithelial corneal collagen cross-linking may potentially affect epithelial cell viability, it is nevertheless not associated with an obvious clinical epithelial defect. We have previously reported the clinical safety and efficacy of higher fluence corneal collagen cross-linking for progressive keratoconus. ${ }^{19}$ Transepithelial corneal collagen cross-linking has been described previously as a treatment for progressive cornea ectasia. ${ }^{20}$ We used transepithelial corneal collagen cross-linking as a means of stabilizing the refractive effect of corneal shrinkage, as described elsewhere. ${ }^{8}$ In order to perform the transepithelial corneal collagen cross-linking, we used $0.1 \%$ riboflavin sodium phosphate drops containing benzalkonium chloride. The purpose of these drops was to loosen the hemidesmosome links between the epithelial cells of the cornea and to allow the large riboflavin molecule to sink into the corneal stroma and achieve collagen cross-linking.

The purpose of sequencing collagen cross-linking in the thermal procedure is to enhance persistence of the collagen shrinkage effect from continuous wave laser application. This procedure has several advantages. One is the ability to titrate the amount of refractive change (+/-) applied to the cornea via number and diameter of the thermal rings applied. Another advantage is that the delivery can be "free form", i.e. these rings can be moved on the applanated surface of the cornea and potentially be centered over any ectatic part of the cornea, and shrink that part of the cornea and flatten the ectasia. "Bow tie" patterns for astigmatic corrections, reported elsewhere, are easily feasible. 


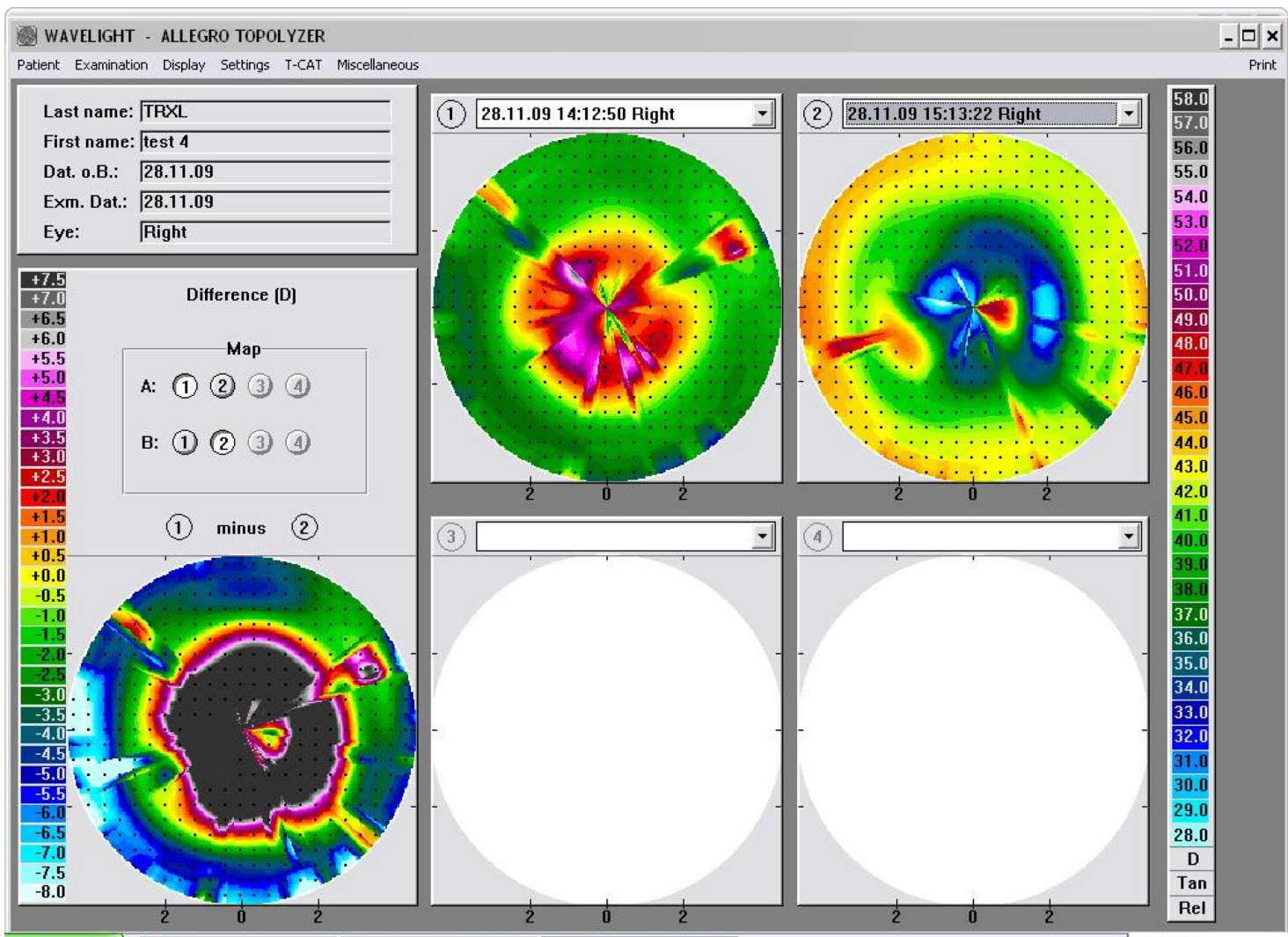

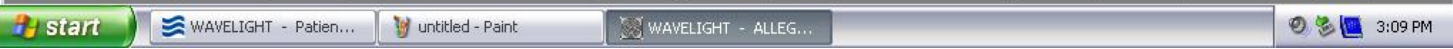

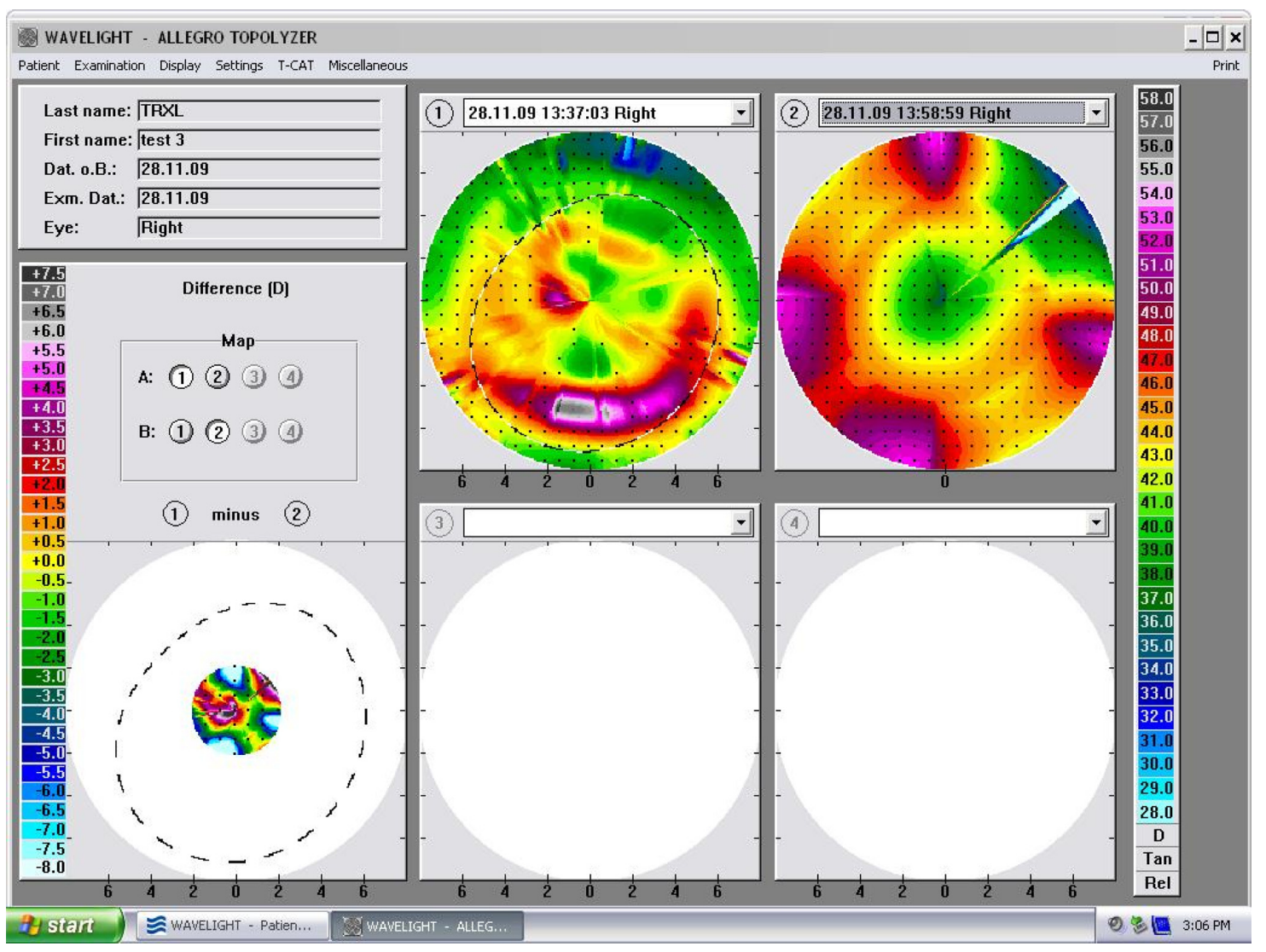

Figures I 2 and I 3 Both these images illustrate the pre- (center) and post- (right) laser treatment corneal topography, as well as the difference (left). The significant central and homogenous hyperopic shift confirms that myopic treatment has been achieved. 

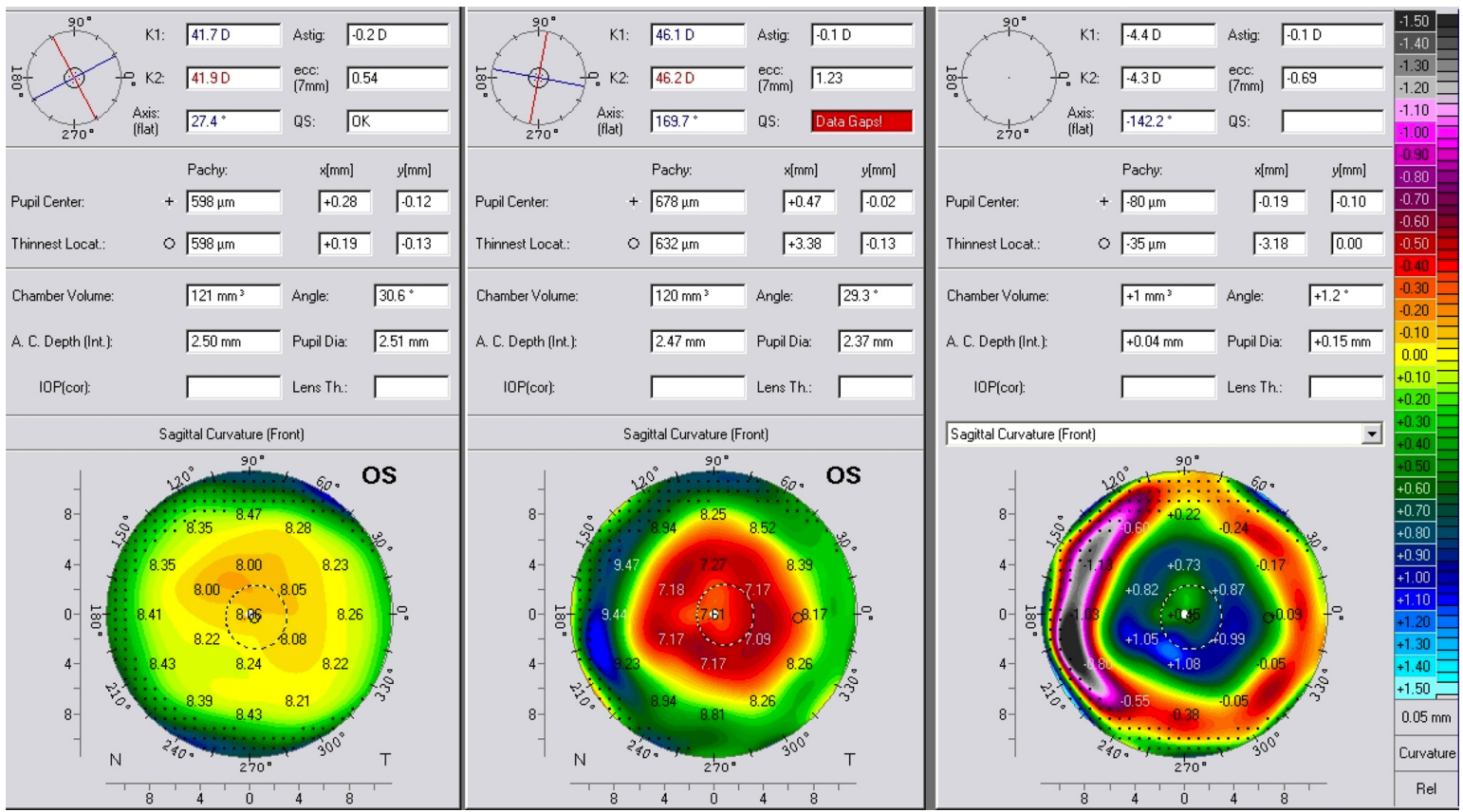

Figure 14 Pre- (left) and post- (middle) laser treatment Scheimflug-generated tomography image (Oculyzer/Pentacam; Wavelight), along with the difference map (right). Significant myopic shift is evident, depicting the symmetric and homogenous refractive corneal shape change.

We have introduced and evaluated clinically the use of topography-guided excimer laser normalization techniques combined with corneal collagen cross-linking, i.e. the Athens protocol, in the treatment of corneal ectasia associated with keratoconus, iatrogenic ectasia, and recently severe cornea scarring. ${ }^{21-27}$ The novel treatment described herein may become an alternative to the Athens protocol, serving potentially the same purpose of normalizing corneal irregularity with customized toric and spherical infrared laser cornea refractive modification and stabilizing the ectasia with

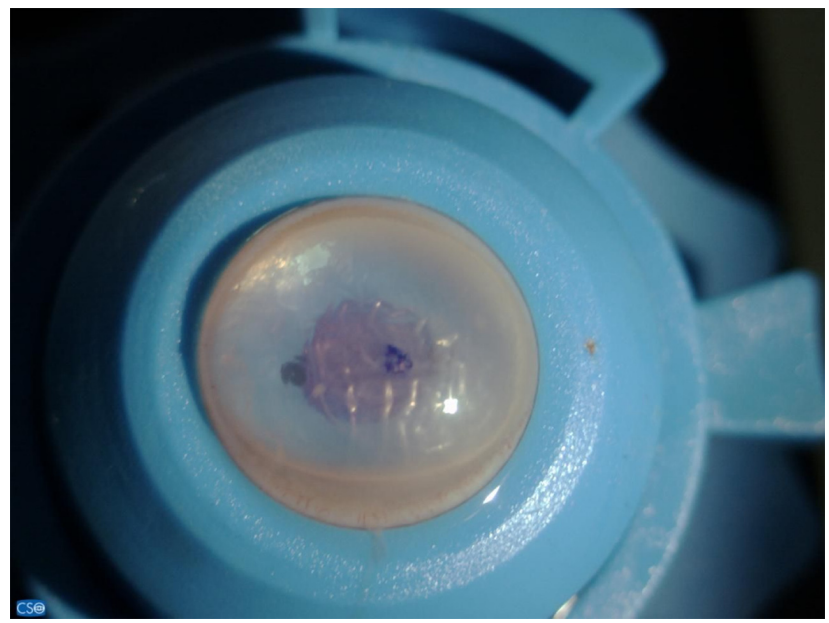

Figure I 5 External view of a treated cornea prior to riboflavin administration and corneal collagen cross-linking, showing again the intact epithelial surface. combined corneal collagen cross-linking, without tissue removal or corneal thinning.

Although not studied herein, the pachymetry requirements of such a treatment may be as low as $350 \mu \mathrm{m}$ in vivo, allowing its application in extreme ectasia. The main difference between this technique and the Keraflex is in essence the lack of epithelial injury and highly titratable nature of the laser application and therefore corneal shrinkage.

\section{Conclusion}

This novel laser and corneal collagen cross-linking treatment appears to be able to both flatten and steepen the cornea, depending on the diameter and depth of laser application, and coupled with transepithelial collagen cross-linking, may provide a novel nonincisional, nonimplanted, sutureless, and essentially pain-free procedure (due to no epithelium defect). Very little discomfort is anticipated in real clinical use postoperatively, and there is a very low risk of infectious complications involving the cornea. Further clinical studies are needed to validate these findings in clinical practice and potentially make this novel procedure a valid alternative for the correction of myopia, hyperopia, astigmatism, and presbyopia, and potentially also as a treatment for stabilization of ectasia.

\section{Disclosure}

This research was presented in part at the 15th Winter Meeting of the European Society of Cataract and Refractive 
Surgeons, Istanbul, Turkey, February 18-20, 2011. The author has served in the past as a nonpaid consultant for Seros Medical (Palo Alto, CA) and is a consultant for Alcon/ Wavelight. The novel infrared laser device, technical assistance, and study design advice were generously provided by Satish Herakar, cofounder of Seros Medical.

\section{References}

1. Stringer H, Parr J. Shrinkage temperature of eye collagen. Nature. 1964;204:1307.

2. Thompson VM, Seiler T, Durrie DS, Cavanaugh TB. Holmium:YAG laser thermokeratoplasty for hyperopia and astigmatism: an overview. Refract Corneal Surg. 1993;9(Suppl 2):S134-S137.

3. Geerling G, Koop N, Tüngler A, et al. Diode laser thermokeratoplasty. Initial clinical experiences. Ophthalmologe. 1999;96(5):306-311. German.

4. Bende T, Jean B, Oltrup T. Laser thermal keratoplasty using a continuous wave diode laser. J Refract Surg. 1999;15(2):154-158.

5. Ren Q, Simon G, Parel JM. Noncontact laser photothermal keratoplasty. III: Histological study in animal eyes. J Refract Corneal Surg. 1994;10(5):529-539.

6. Parel JM, Ren Q, Simon G. Noncontact laser photothermal keratoplasty. I: Biophysical principles and laser beam delivery system. $J$ Refract Corneal Surg. 1994;10(5):511-518.

7. Ehrlich JS, Manche EE. Regression of effect over long-term follow-up of conductive keratoplasty to correct mild to moderate hyperopia. J Cataract Refract Surg. 2009;35(9):1591-1596.

8. Kato N, Toda I, Kawakita T, Sakai C, Tsubota K. Topography-guided conductive keratoplasty: treatment for advanced keratoconus. Am J Ophthalmol. 2010;150(4):481-489.

9. Kymionis GD, Kontadakis GA, Naoumidi TL, Kazakos DC, Giapitzakis I, Pallikaris IG. Conductive keratoplasty followed by collagen crosslinking with riboflavin-UV-A in patients with keratoconus. Cornea. 2010;29(2):239-243.

10. Horn G, Spears KG, Lopez O, et al. New refractive method for laser thermal keratoplasty with the Co: MgF2 laser. J Cataract Refract Surg. 1990;16(5):611-616.

11. Koch DD. Histological changes and wound healing response following noncontact holmium: YAG laser thermal keratoplasty. Trans Am Ophthalmol Soc. 1996;94:745-802.

12. Ariyasu RG, Sand B, Menefee R, et al. Holmium laser thermal keratoplasty of 10 poorly sighted eyes. J Refract Surg. 1995;11(5): 358-365.

13. Neumann AC, Fyodorov S, Sanders DR. Radial thermokeratoplasty for the correction of hyperopia. Refract Corneal Surg. 1990;6(6): 404-412.
14. Hatch JL. Thermal wedge with penetrating keratoplasty to reduce high corneal cylinder. Am J Ophthalmol. 1980;90(2):137-141.

15. Barsam A, Patmore A, Muller D, Marshall J. Keratorefractive effect of microwave keratoplasty on human corneas. J Cataract Refract Surg. 2010;36(3):472-476.

16. Pearce JA, Panescu D. Radiofrequency conductive keratoplasty in the cornea: prediction of diopter changes in numerical models. Conf Proc IEEE Eng Med Biol Soc. 2004; 7:5426-5429.

17. Trembly BS, Keates RH. Combined microwave heating and surface cooling of the cornea. IEEE Trans Biomed Eng. 1991;38(1):85-91.

18. Kanellopoulos AJ. The management of cornea blindness from severe corneal scarring, with the Athens protocol (transepithelial topographyguided PRK therapeutic remodeling, combined with same-day, collagen cross-linking). Clin Ophthalmol. 2012;6:87-90.

19. Mainster MA. Ophthalmic applications of infrared lasers - thermal considerations. Invest Ophthalmol Vis Sci. 1979;18(4):414-420.

20. Kanellopoulos AJ. Long term results of a prospective randomized bilateral eye comparison trial of higher fluence, shorter duration ultraviolet A radiation, and riboflavin collagen cross linking for progressive keratoconus. Clin Ophthalmol. 2012;6:97-101.

21. Caporossi A, Mazzotta C, Baiocchi S, Caporossi T, Paradiso1 AL. Transepithelial corneal collagen crosslinking for keratoconus: qualitative investigation by in vivo HRT II confocal analysis. Eur $J$ Ophthalmol. February 17, 2012. [Epub ahead of print.]

22. Kanellopoulos AJ. Post-LASIK ectasia. Ophthalmology. 2007; 114(6):1230.

23. Kanellopoulos AJ, Skouteris VS. Secondary ectasia due to forceps injury at childbirth: management with combined topography-guided partial PRK and collagen cross-linking (Athens protocol) and subsequent phakic IOL implantation. J Refract Surg. 2011;27(9):635-636.

24. Kanellopoulos AJ, Binder PS. Management of corneal ectasia after LASIK with combined, same-day, topography-guided partial transepithelial PRK and collagen cross-linking: the Athens protocol. $J$ Refract Surg. 2011;27(5):323-331.

25. Krueger RR, Kanellopoulos AJ. Stability of simultaneous topography-guided photorefractive keratectomy and riboflavin/UVA cross-linking for progressive keratoconus: case reports. $J$ Refract Surg. 2010;26(10):S827-832.

26. Kanellopoulos AJ. Comparison of sequential vs same-day simultaneous collagen cross-linking and topography-guided PRK for treatment of keratoconus. J Refract Surg. 2009;25(9):S812-S818.

27. Kanellopoulos AJ, Binder PS. Collagen cross-linking (CCL) with sequential topography-guided PRK: a temporizing alternative for keratoconus to penetrating keratoplasty. Cornea. 2007;26(7): 891-895.
Clinical Ophthalmology

\section{Publish your work in this journal}

Clinical Ophthalmology is an international, peer-reviewed journal covering all subspecialties within ophthalmology. Key topics include: Optometry; Visual science; Pharmacology and drug therapy in eye diseases; Basic Sciences; Primary and Secondary eye care; Patient Safety and Quality of Care Improvements. This journal is indexed on Submit your manuscript here: http://www.dovepress.com/clinical-ophthalmology-journal

\section{Dovepress}

PubMed Central and CAS, and is the official journal of The Society of Clinical Ophthalmology (SCO). The manuscript management system is completely online and includes a very quick and fair peer-review system, which is all easy to use. Visit http://www.dovepress.com/ testimonials.php to read real quotes from published authors. 